\title{
Optics for everyone: measuring the results after five years of work
}

Perla Marlene Viera-González, Jose Ismael MartínezContreras, Guadalupe Ponce-Hernández, Guillermo Ezequiel Sánchez-Guerrero

Perla Marlene Viera-González, Jose Ismael Martínez-Contreras, Guadalupe Ponce-Hernández, Guillermo Ezequiel Sánchez-Guerrero, "Optics for everyone: measuring the results after five years of work," Proc. SPIE 11143, Fifteenth Conference on Education and Training in Optics and Photonics: ETOP 2019, 111433Q (2 July 2019); doi: 10.1117/12.2523854 


\title{
Optics for everyone: measuring the results after five years of work
}

\author{
Perla Marlene Viera-González ${ }^{\mathrm{a}}$, Jose Ismael Martínez-Contreras ${ }^{\mathrm{a}}$, Guadalupe \\ Ponce-Hernández ${ }^{\mathrm{a}}$, and Guillermo Ezequiel Sánchez-Guerrero ${ }^{\mathrm{a}}$ \\ ${ }^{a}$ Facultad de Ciencias Fisico Matematicas, Universidad Autonoma de Nuevo Leon, Av. \\ Universidad SN Cd. Universitaria, San Nicolas de los Garza, Nuevo Leon, Mexico
}

\begin{abstract}
The group Physics for everyone, a group created by former members of the SPIE student chapter of the Universidad Autonoma de Nuevo Leon, have been conducting activities for kids, teenagers and the general public through the program "Optics for everyone" since its creation in 2013. The objectives of this group and this program are to teach the importance of light, optics, and photonics to understand the world where we lived and the advances in technology. Also, the group prepares undergraduate students to learn and teach optics and photonics before taking the corresponding curricular courses, conducting to a new approach of how to understand the light interactively. This work presents a summary of the activities performed during five years, the outcomes obtained, the number of people reached, the experience of the volunteers and the conclusions and future work of the program and the group. Among the outstanding contributions of the programs is included the performance of optics and photonics workshops in public schools and public places, including unprivileged and remote communities in the state of Nuevo Leon, Mexico.
\end{abstract}

Keywords: Optics and Photonics education, informal education, optics for kids, undergraduate project

\section{INTRODUCTION}

Professional societies as the SPIE, the Optical Society (OSA) and the Institute of Electrical and Electronics Engineers (IEEE) sponsor student chapters in order to foster scholarship and training in STEM fields at the college and graduate level, but they are also an excellent resource for disseminating STEM knowledge to precollege students and teachers. ${ }^{1}$

On this subject, former members of the SPIE Student Chapter of the Universidad Autónoma de Nuevo León created a Science Outreach group called "Physics for everyone" (in Spanish Física Pato2) in November 2013 with the clear objective that anyone can have access to learn Science, especially Physics, in a fun and interactive way. ${ }^{2,3}$

The "Physics for everyone" philosophy is that anyone can join the group and learn how to perform STEM demonstrations and experiments, always with the support of the other members, improving the personal learning of the volunteers who looks increase the positive reactions of the public in his/her activities during our events. Our volunteers are, in general, Physics, Math, Computer Sciences and Engineering students that love Science and wants that more people can understand its underlying phenomena and its importance in our lives.

The group works under the concept of learning service, that is one of the objectives of the educational programs in the Universidad Autónoma de Nuevo León (UANL); this concept implies that a person will be able to teach something to a non-technical audience if he/she really understand the topic ${ }^{4}$ and it is used as the tool to disseminate the word about the research work and industrial projects done by the UANL.

As former members of an SPIE Student Chapter, one of the main goals of the group is to spread the word about the importance of Light, Optics, and Photonics as the base to learn about the Universe, technology and daily life phenomena. ${ }^{3}$ With this in mind, the program "Optics for everyone" was developed and has been in constant improvement since its implementation in 2014.

Further author information: (Send correspondence to P.M.V.G.)

P.M.V.G.: E-mail: perla.vieragn(at)uanl.edu.mx

Fifteenth Conference on Education and Training in Optics and Photonics: ETOP 2019, edited by

Anne-Sophie Poulin-Girard, Joseph A. Shaw, Proc. of SPIE Vol. 11143, 111433Q · C 2019

SPIE, ICO, IEEE, OSA·CCC code: 0277-786X/19/\$18 · doi: 10.1117/12.2523854

Proc. of SPIE Vol. 11143 111433Q-1 


\section{PROGRAM: OPTICS FOR EVERYONE}

Science education not only is about how children and youth learn Science as the only outcome pursued by the process of teaching. Indeed, it is necessary to understand the meaning of learning Science as part of human knowledge, relate its branches not isolate them and develop the potential of all students. In this regard, the program "Optics for everyone" is a cross-disciplinary educational and outreach project where students of different STEM fields of the UANL perform scientific demonstrations and experiments where the public interact with the objective to enjoy the experience and enforce, in a positive way, that do science is interesting and even fun. ${ }^{3,5}$

This program is based on:

- Light is everywhere.

- Light and its study through Optics and Photonics are important to understand technology nowadays.

- Science is a way of culture and can be used as artistic expression.

- Anyone can learn about Light, Optics and Photonics.

- Anyone can be a volunteer to teach about Light, Optics and Photonics; you only need to understand, study and practice your favorite light phenomena.

- The learning of concepts is not the only objective while learning science.

- The learning of sciences must have meaningful learning with favorable conditions and cognitive structure. ${ }^{6}$

- Teaching must be part of the program's volunteers formation by including concepts, values, and attitudes in a process where the volunteer meet itself, the surroundings, and learn how to socialize. ${ }^{7}$

\subsection{Educational approach}

Even this is an informal program for teaching science, the first step of the strategy, use the constructivism as the main factor for the activities because as many authors stands, the learning is a process where the link between the experiences and ideas meet, moreover, the ideas must be linked to complete a knowledge of the world. ${ }^{8}$ As a second step, the Active Learning of Optics (ALOP) philosophy was implemented on the hands-on activities, inspired in other successful works. ${ }^{9,10}$ On the other hand, to complement the hands-on activities, the program includes demonstrations that are focused on the concepts and usually were not inexpensive because the main objective was to demonstrate a concept and link it with the hands-on activities.

\subsection{Activities}

Different demonstrations, experiments, and hands-on activities (Fig. 1)are included in the program which covers the next topics: ${ }^{2,3,11}$

- Electromagnetism

- Waves

- Color

- Refraction, reflection, and diffraction

- Lenses and geometrical optics

- Lasers

- Moire patterns and Optical illusions

- Polarization

- Astronomy

In addition to the activities for kids and the general public, the program "Optics for everyone" has adopted the project "Dumpster Optics" for train teachers and volunteers of the program during the past two years ${ }^{11}$ as it is shown in Fig. 2. 


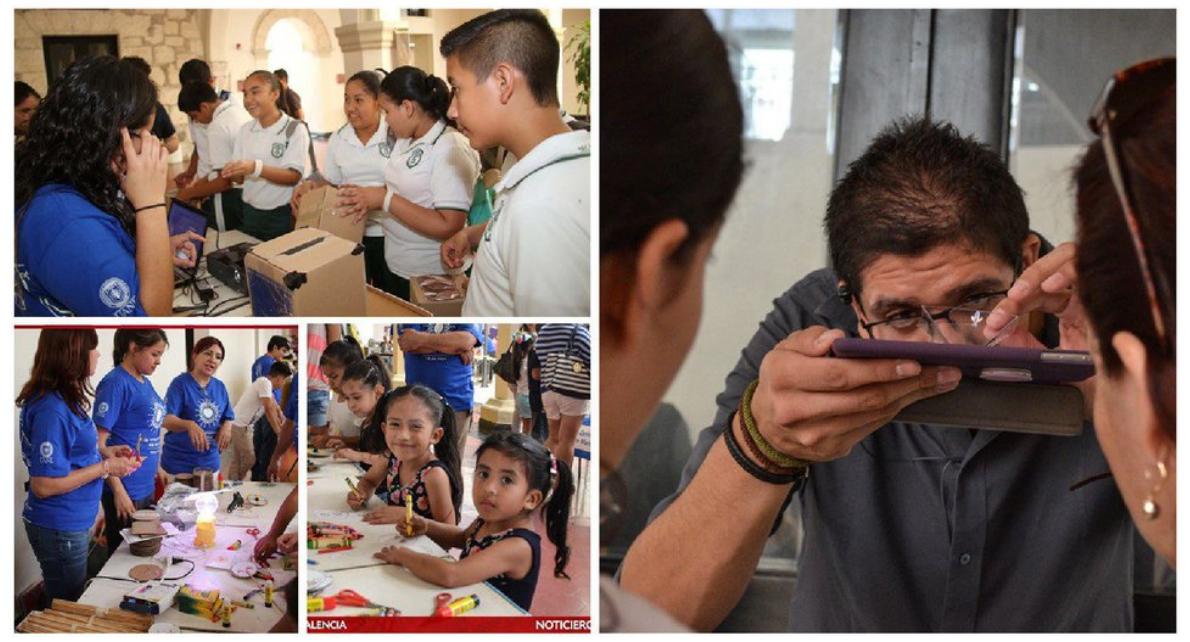

Figure 1. Examples of hands-on optics activities performed during our events.
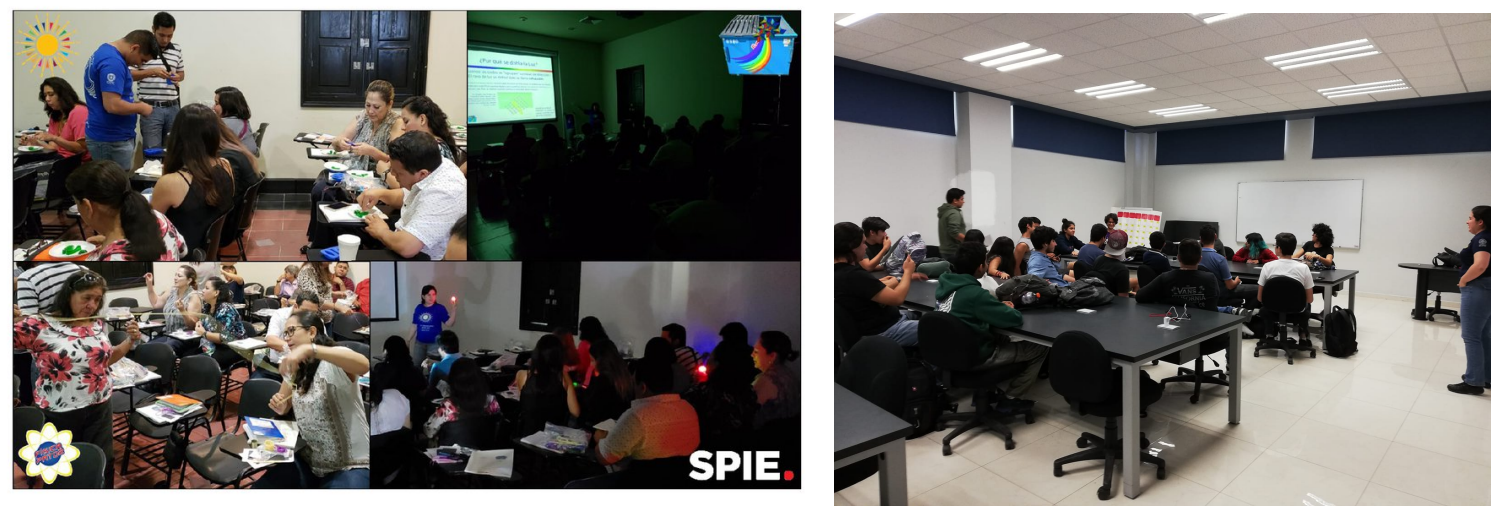

Figure 2. a) Dumpster Optics Workshop 2018. b) Physics for everyone volunteers taking training in fall 2018

\subsection{Events}

The topics mentioned above and the activities conducted such as demonstrations, hands-on activities, lecturers, scientific plays, games and artistic performances have been presented in different kind of events as:

- School visits. It is a way to perform Optics and Photonics demonstrations in a controlled environment, where the teachers support the learning process and provide guidance during the activities. These events are usually conducted in the classroom and are used as a complement of the curricula topics and are limited in time.

- Public events. These events follow a format similar to a Science fair where families can participate in different activities; the objective is to involve the whole family in the workshop and are more flexible in time and format.

- Workshops. These events are limited to teachers, home school parents, and volunteers, this is the main tool of the group to increase our impact by training people to perform hands-on activities and scientific demonstrations.

- Events related to the International Year of Light and the International Day of Light (Fig. 3). Are usually related to public events, but the main objective is to show the light in a cross-disciplinary environment 
and include artistic and cultural activities related to Light.
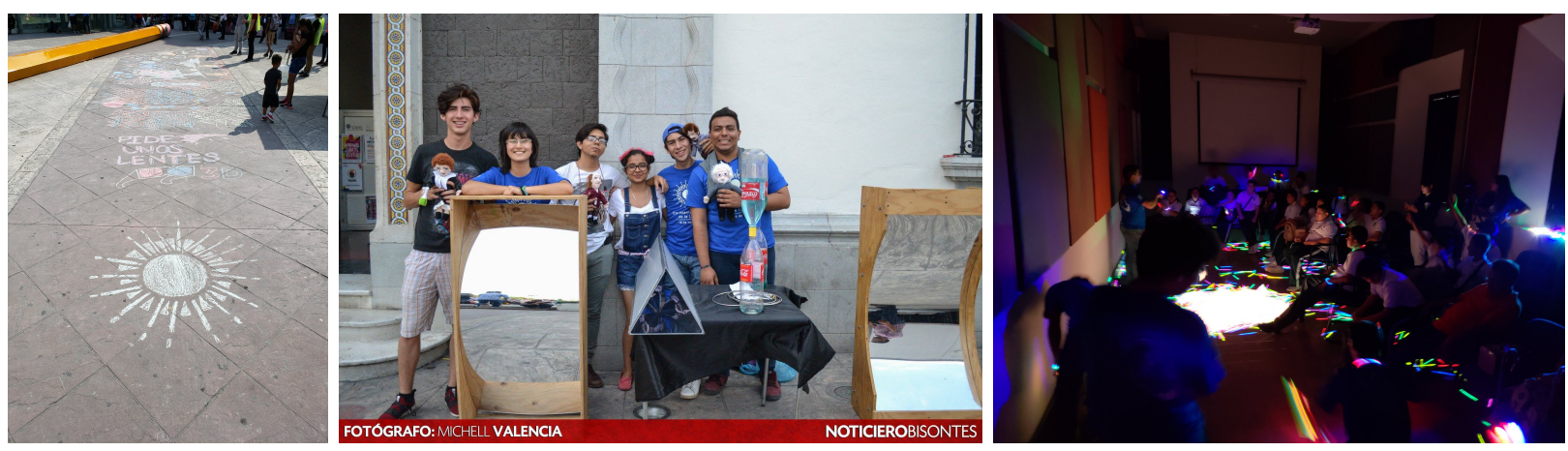

Figure 3. International Day of Light events that include artistic and cultural activities

The implementation of the different activities in all the kind of events mentioned above, including the workshops for teachers and volunteers, has, as a result, more than 70 events that have involved more than 333 as volunteers as can be seen in the next section.

\section{RESULTS}

Since November 2013, the group Physics for everyone through the program Optics for everyone is looking to increase the interest in Science in Nuevo León, including remote communities.

\subsection{Outcomes}

The program Optics for everyone includes 125 events, including visits to schools, public events and three workshops for teachers and home school parents and two multi-day workshops for volunteers since November 2013 to March 2019, the summary of this events can be seen in the Table 1 and it is shown in the figures 4 and 5 .

Table 1. "Optics for everyone" events.

\begin{tabular}{|c|c|c|}
\hline Year & Events & People \\
\hline 2013 & 1 & 100 \\
\hline 2014 & 21 & 3400 \\
\hline 2015 & 15 & 9300 \\
\hline 2016 & 14 & 6500 \\
\hline 2017 & 39 & 35000 \\
\hline 2018 & 25 & 15750 \\
\hline 2019 & 12 & 10500 \\
\hline
\end{tabular}

Table 1 shows that the number of events and the people reached has been increased every year, having more than 80,500 people reached in 5 years. The increase in the number of people reached in 2017 was due to the massive event for the Solar Eclipse where more than 15000 people participated in the astronomic observations. Fig. 6 shows the audience of the events and highlights that our target audience are the kids and teenagers.

The events include visits to remote communities such as Dr. Arroyo, García, Linares, Santiago, Galeana, Montemorelos and specialized education centers as the Instituto Down Monterrey and orphanages. 

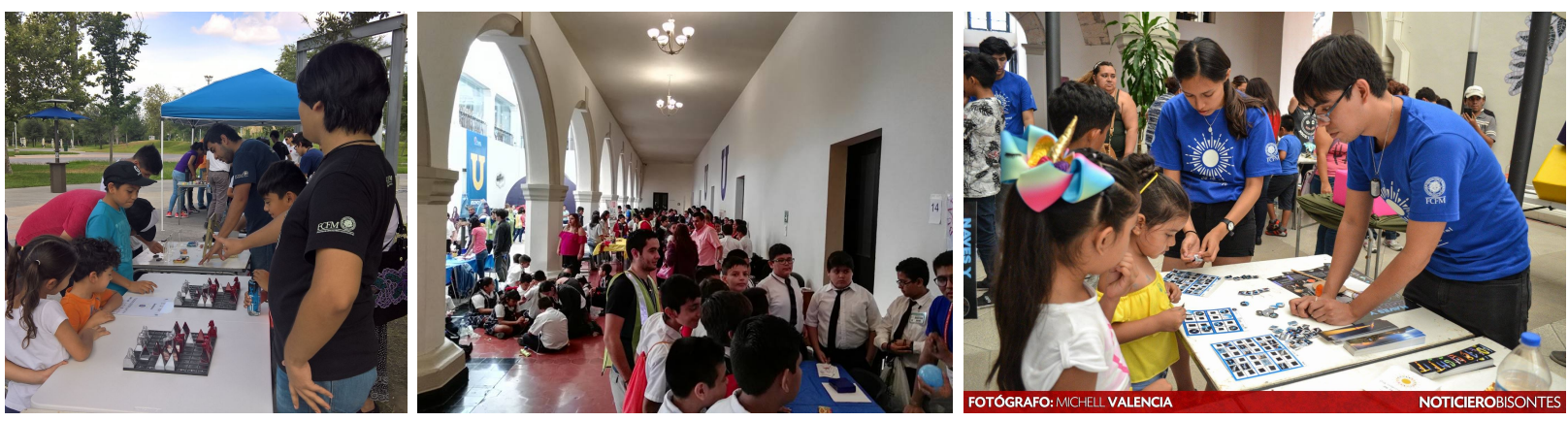

Figure 4. Public events.
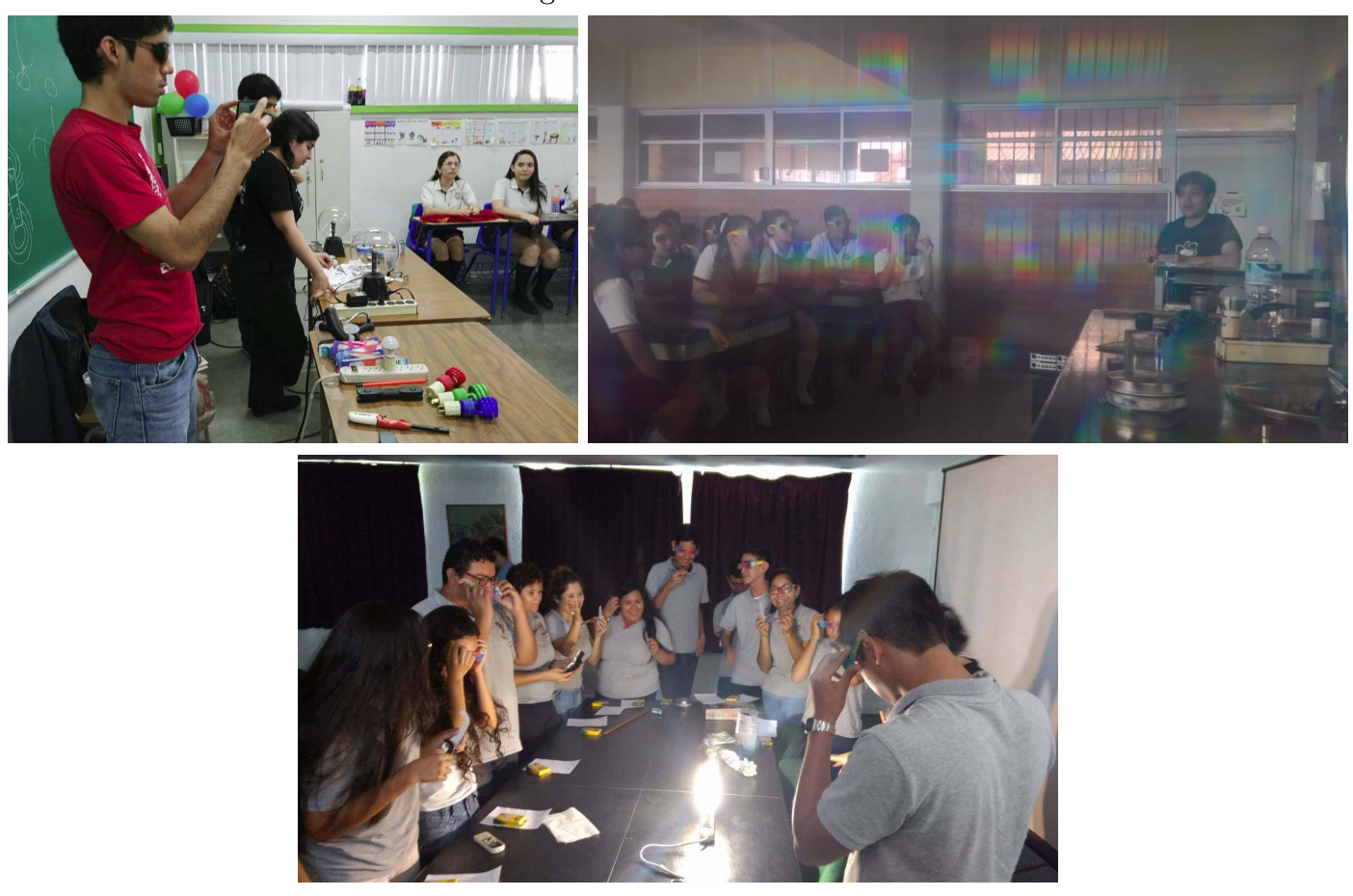

Figure 5. Visits to schools.

\subsection{Volunteers}

The group Physics for everyone began with no more than ten volunteers that celebrated the non-official "Physicist Day" in our country with a Science Outreach event in the Instituto Down Monterrey in December 2013 (Fig. 7). Since then, we use as one of the measures of our impact the number of volunteers that help us in every event. Fig. 8 shows how the number of people that have helped in the program has grown every year.

Another significant result of the program is not only the number of volunteers involved, but it is also the skills our volunteers developed, such as work in teams, leadership, problem-solving, effective communication, event organization, teaching skills, develop outreach materials, among others. Also, most of our volunteers have reported that it is easier for them to learn Optics or other Science subjects in their academic curricular after conducting STEM outreach activities for one year or more. Other important skill, is conducting experiments in research laboratories because they developed mechanical abilities in the construction of outreach materials and performing science demonstrations, that allow them to get used to handling lab equipment efficiently. Finally, some of the volunteers that look for a job just after gained his/her bachelor degree find that is easy for them to work as basic education teachers or as staff in Science Museums. 


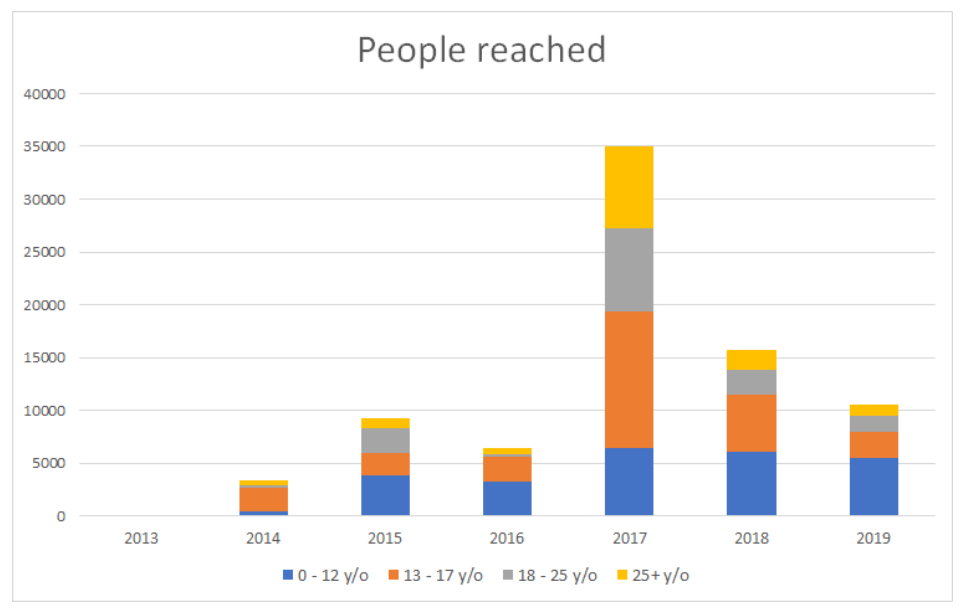

Figure 6. The graph shows the total of people reached every year according to its age.

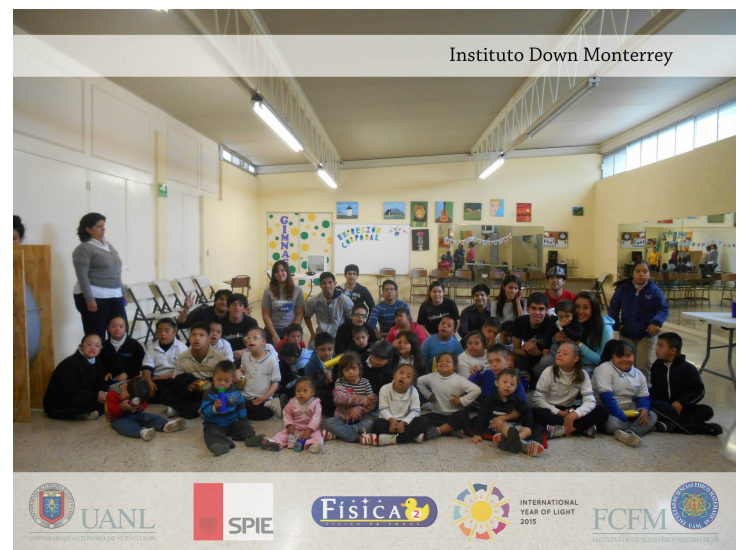

Figure 7. First activity of the program Optics for everyone at the Instituto Down Monterrey.

\subsection{Joint projects}

The success of the program allowed the group Physics for everyone to join other important national projects with the Light, Optics and Photonics activities such as:

- Co-leading the National Week of Science and Technology in Nuevo León with the Astronomy group of the UANL.

- Participate every year in the International event "Starring night".

- Support the Education Ministry in Nuevo León in the program "Science in family".

- Participate in the National Meeting of Science Outreach Professionals.

- Be part of the National Network of Science Professionals (Recreación en Cadena) and participate in the national initiative "Suma Ciencia" (More Science).

\section{CONCLUSIONS}

The program Optics for everyone has been very successful because the number of people interested in participating or volunteering in the program has grown every year, also, every month we received invitations to visits schools 


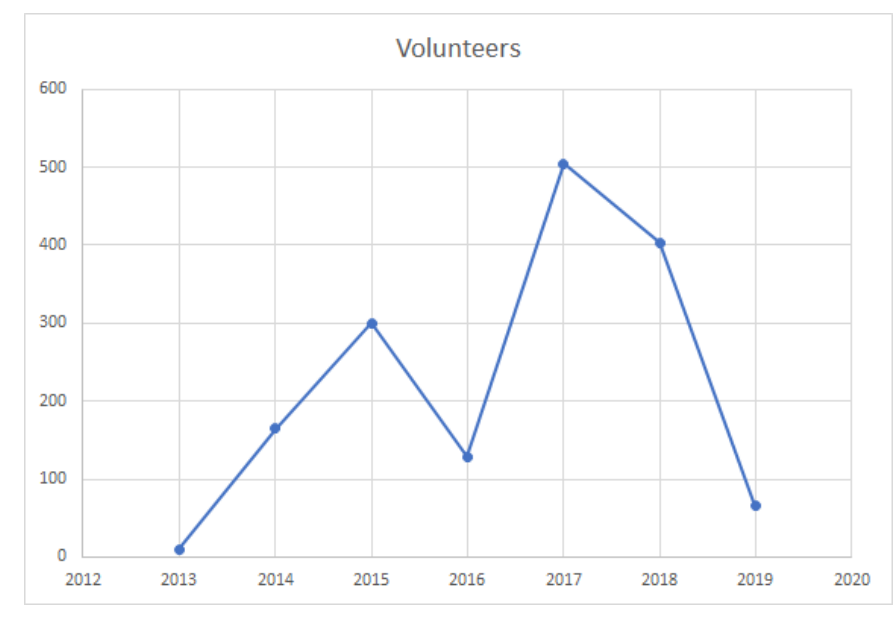

Figure 8. Volunteers of the program Optics for everyone by year.

in our state, and there are more teachers interested in taking workshops with us. Besides, we are constantly increasing and improving our activities to maintain the interest of the kids and families in our events.

We have been taken into account to participate in important Science initiatives in our state and our country, showing that we are doing a good job and we are considering one of the main Science Outreach groups in our Faculty and University.

\subsection{Future work}

The next step in this project is to improve our activities including more STEM activities that involve technology to increase the interest in the activities and involve other skills as the use of computers or electronics in the process of learning about Light. Besides, we are looking for effective ways to measure the impact and the quality of our activities.

The program "Optics for everyone" is not a work finished yet, but we will continue working to improve our activities and increase the awareness about Light, Optics and Photonics.

\section{ACKNOWLEDGMENTS}

The program "Optics for everyone" has been supported by the International Society for Optics and Photonics SPIE through the SPIE Education Outreach Grant Program since 2014 and by the IEEE Photonics Society, since 2017. Also, the Facultad de Ciencias Físico Matemáticas of the Universidad Autónoma de Nuevo León has provided the facilities to allow the success of the group "Physics for everyone".

\section{REFERENCES}

[1] Dirk Fabian, N. V. and Overmeire, S. V., "Student chapters: effective dissemination networks for informal optics and photonics education," 9666 (2009).

[2] P. Viera-Gonzlez, G. Snchez-Guerrero, J. R.-M. G. C.-O. D. C.-H. R. S.-A., "Optics outreach activities with elementary school kids from public education in mexico," 9188 (2014).

[3] Perla M. Viera-Gonzlez, G. E. S.-G., "Optics 4 every1, the hands-on optics outreach program of the universidad autonoma de nuevo leon," 9946 (2016).

[4] UANL, "Modelo académico técnico superior universitario, profesional asociado y licenciatura de la uanl," (2015).

[5] Ruiz-Mendoza, J., Alternativa metodológica para la formación integral de los estudiantes desde el proceso de enseñanza de la Física, PhD thesis, Universidad de Camagüey (2005).

[6] Gagné, R. M., Ausubel, D. P., and Gagne, R. M., "Educational Psychology: A Cognitive View," American Educational Research Journal 6, 287 (mar 1969). 
[7] Torres, A., Ruíz, J. C., and Alvarez, N., "La autotransformación del estudiante universitario : más allá de la formación integral," Revista Iberoamericana de Educación 43, 2-9 (2007).

[8] Arango, C. M. G., "La enseñanza de la óptica desde una conceptualización integradora de sus teorías, dinamizada y orientada por una concepción del aprendizaje significativo crítico," documento de trabajo, Universidad Nacional de Colombia, Medellín, Medellín (2013).

[9] Alarcon, M., Ben Lakhdar, Z., Culaba, I., Lahmar, S., Lakshminarayanan, V., Mazzolini, A. P., Maquiling, J., and Niemela, J., "Active learning in optics and photonics (ALOP): a model for teacher training and professional development," 7783, 778303-778303-8 (aug 2010).

[10] Marín, D. P. V., "Estudio del impacto didáctico de la metodología "de aprendizaje activo" en la enseñanza de la óptica," documento de trabajo, Universidad Nacional de Colombia, Sede Medellín (Junio 2012).

[11] Perla Marlene Viera-Gonzlez, G. E. S.-G., "Idl in monterrey: science, art and culture of light," 10741 (2018). 